\title{
Percutaneous coronary intervention in treatment of multivessel coronary artery disease in patients with non-ST-segment elevation acute coronary syndrome
}

\author{
Paweł Gąsior', Piotr Desperak², Karolina Gierlaszyńska², Michał Hawranek², Marek Gierlotka², Mariusz Gąsior², \\ Lech Poloński \\ ${ }^{1}$ Medical University of Silesia, Katowice, Poland \\ $2^{2}$ rd Department of Cardiology, Medical University of Silesia, Silesian Centre for Heart Diseases, Zabrze, Poland
}

Postep Kardiol Inter 2013; 9, 2 (32): 136-145

DOI: 10.5114/pwki.2013.35448

\begin{abstract}
Among patients with non-ST-elevated acute coronary syndromes (NSTE-ACS) the estimated percentage of single vessel coronary artery disease (SV-CAD) observed during coronarography is about $20-40 \%$, while multivessel coronary artery disease (MV-CAD) is found in about $40-60 \%$. Further treatment in patients with both SV CAD and MV CAD is usually culprit vessel percutaneous coronary intervention (CV-PCI). Nevertheless, in the group of patients with MV-CAD there is still a problematic decision whether the non-infarct related arteries (non-IRA) should be treated with PCI. According to the European Society of Cardiology (ESC) guidelines on myocardial revascularization this decision should be based on the overall clinical and angiographic status of the patient; simultaneously they suggest performing ad hoc CV-PCI. The decision of performing intervention in the rest of the narrowed coronary arteries should be made after consultation with the heart team or according to the protocols adopted in the specific clinic. Furthermore, there is a question of whether the procedure should be performed immediately after culprit vessel revascularization or it should be postponed until the patient is stabilized. Due to the lack of specific recommendations we decided to perform an analysis of existing studies which compared culprit versus multivessel revascularization in patients with MV-CAD and non-ST-elevated acute coronary syndromes.
\end{abstract}

Key words: non-ST-elevated acute coronary syndrome, multivessel coronary artery disease, percutaneous coronary intervention.

\section{Introduction}

Current epidemiological data indicate more frequent occurrence of non-ST-elevation acute coronary syndromes (NSTE-ACS) than ST-segment elevation myocardial infarction (STEMI) [1, 2]. Large diversity of presented clinical symptoms and outcomes is characteristic for the NSTE-ACS population. Therefore an essential element both in diagnosis and in the selection of an optimal therapeutic strategy is estimation of cardiovascular risk. It has been proven that suitable stratification enables one to separate patients from the low risk group where conservative treatment seems to be favorable and from the high risk group in which invasive diagnostics and treatment are necessary [3-5].

Several meta-analyses have demonstrated that choosing the early invasive strategy provides measurable benefits in reduction of adverse cardiovascular events [6-10], including death from any cause in long-term follow-up [7].
Among patients with NSTE-ACS who underwent coronary angiography the percentage of single and multivessel coronary artery disease (MV CAD) is respectively $20-40 \%$ and $40-60 \%[4,11-15]$. Both in the first and second case the further procedure is usually percutaneous coronary intervention $(\mathrm{PCl})$ of the culprit vessel [16-18]. However, in the MV CAD population the decision on performing an interventional procedure in the remaining narrowed vessels, which are not the direct cause of NSTE-ACS, is still a problematic issue. Furthermore, the question arises whether any intervention should be accomplished immediately after culprit vessel angioplasty or postponed to clinical condition stabilization?

It should be emphasized that the preferred method of managing multivessel coronary artery disease recommended by the European Society of Cardiology (ESC) is coronary artery bypass grafting (CABG) [17]. Nevertheless, the results of recent studies indicate that $\mathrm{PCI}$ can be per-

Corresponding author:

Paweł Gąsior, Medical University of Silesia, 15 Poniatowskiego St, Katowice, Poland, tel.: +48 600 429 867, e-mail: p.m.gasior@gmail.com Received: 9.01.2013, accepted: 9.05.2013. 
formed as an alternative method to cardiac surgery in patients with low and intermediate SYNTAX Scores [18, 19].

\section{Potential benefits and risks from each strategy}

At the beginning it is worth noting that MV CAD itself is associated with lower rates of successful revascularization, an increased number of complications and consequently with worse in-hospital and long-term outcomes $[20,21]$. Therefore, in contrast to lesions restricted to a single coronary artery, the further decision-making process on the optimal treatment strategy is more complex. Technical development especially in the field of coronary artery stents caused an increase in the number of $\mathrm{PCl}$ procedures among patients with MV CAD, which in some situations constitutes a valuable alternative to CABG [17, 19, 22].

As noted earlier, after culprit vessel revascularization in the course of MV CAD the interventional cardiologist is forced to decide whether to expand the procedure to the remaining significantly narrowed vessels or to end it. Both strategies carry potential, often different risks and benefits. The foregoing dilemma does not apply to patients with cardiogenic shock, since the guidelines recommend complete myocardial revascularization, with $\mathrm{PCl}$ performed in all critically stenosed large epicardial territories.

Acute coronary syndromes cause many local and systemic pathophysiological processes, such as increased adrenergic activity, which manifest in presence of vascular spasm especially in atherosclerotic vessels [23]. The vasospastic component with endothelial dysfunction leads to overestimation of stenosis severity in coronary angiography [24]. In some cases, during multivessel revascularization (MVR) this condition can result in unnecessary angioplasty in non-significantly stenosed vessels. Moreover, considering the prothrombotic [25] and proinflammatory state [26] it should be noted that a substantial increase of early thrombosis and restenosis risk is proportional to the number of implanted stents $[27,28]$. The MVR can also lead to prolongation of procedure time, exposure to a higher radiation dose and larger volume of contrast agents compared to culprit vessel revascularization. This may result in an increased number of complications such as periprocedural bleeding, myocardial infarction or acute kidney injury, especially among patients with low cardiovascular risk. It is often associated with poorer in-hospital and long-term outcomes [29-35]. On the other hand, instability of atherosclerotic plaque during acute coronary syndrome is not necessarily limited to the culprit vessel [36]. Most importantly, more complex intervention can reduce the number of adverse cardiovascular events, especially by limiting future revascularization and rehospitalization.

In the course of multivessel NSTE-ACS, one of the possibilities after culprit vessel angioplasty is to postpone the procedure of the remaining stenosed vessels. Postponed intervention can be performed during the same hospital- ization or delayed after hospital discharge. This solution provides stabilization of the patient and allows heart team to reassess the clinical and angiographic state. Additional data can be provided by conducting noninvasive stress tests, which can be helpful in further diagnosis of ischemia caused by stenosis not related to the culprit vessel. However, postponing the procedure comes with greater risk of complications associated with the following procedure and possible repeat hospitalization.

Due to those issues based on the whole spectrum of acute coronary syndromes, we decided to analyze in detail scientific reports on efficacy and safety of presented strategies on managing patients with NSTE-ACS and MV CAD.

\section{Methods}

We analyzed original papers available in the PubMed database using the following key words: 'acute coronary syndromes', 'multivessel coronary disease', and 'percutaneous coronary intervention'. We also analyzed societies of cardiology guidelines ESC/ACCF/AHA for references related to the discussed subject [16-18].

Commonly MV CAD is defined as presence of at least 2 hemodynamically significant narrowed major epicardial arteries during angiography. Depending on the study a diameter stenosis of $>50 \%$ or $>70 \%$ was considered significant in vessels larger than $1.5 \mathrm{~mm}$. In analyzed studies culprit vessel $\mathrm{PCI}(\mathrm{CV} \mathrm{PCl})$ was defined as revascularization of every significant stenosis in the artery responsible for ischemia in NSTE-ACS, whereas multivessel PCI (MV PCI) was defined as revascularization in $>1$ major epicardial vessel during a single procedure. In some articles, the MV $\mathrm{PCl}$ group included patients who underwent a staged procedure during single hospitalization [41, 45, 47]. In all cases the decision on choosing the revascularization strategy was undertaken by the operator. The remaining definitions on the discussed subject are available in relevant papers [37-47]. Gathered scientific data based on hospital and national registries are shown in Table 1.

\section{Baseline clinical characteristics of analyzed groups}

Clinical characteristics of both groups are shown in Table 2. Brener's and Bauer's studies showed that patients who undergo CV PCl are significantly older and more frequently diagnosed with non-ST-segment elevation myocardial infarction (NSTEMI) than patients from the MV PCI group $[43,46]$. Also in the CV PCI group they noted more frequent occurrence of hypertension, peripheral vascular disease and cigarette smokers. Furthermore, Brener observed more frequent presence of renal failure and prior $\mathrm{PCl}$, whereas Bauer noted lower presence of hypercholesterolemia and heart failure in the $\mathrm{CV} \mathrm{PCI}$ group. In other studies baseline characteristics were similar between both groups [41, 42, 44, 45]. It is worth noting that patients from the $\mathrm{CV} \mathrm{PCl} \mathrm{group} \mathrm{were} \mathrm{more} \mathrm{burdened} \mathrm{in} \mathrm{terms} \mathrm{of}$ 
Table 1. Characteristics of previous studies in patients with non-ST-elevation acute coronary syndromes and multivessel coronary artery disease

\begin{tabular}{|c|c|c|c|c|c|c|c|c|}
\hline $\begin{array}{l}\text { First } \\
\text { investigator } \\
\text { of study }\end{array}$ & Year & $\begin{array}{l}\text { Inclusion } \\
\text { criteria }\end{array}$ & $\begin{array}{l}\text { Hemodynamic } \\
\text { significance } \\
\text { of lesion }\end{array}$ & $\begin{array}{l}\text { Exclusion } \\
\text { criteria }\end{array}$ & $\begin{array}{l}\text { Number } \\
\text { of patients } \\
\text { in the study }\end{array}$ & $\begin{array}{c}\text { Number } \\
\text { of patients with } \\
\mathrm{CV} / \mathrm{MV} \mathrm{PCl}\end{array}$ & Follow-up & End points \\
\hline Brener [41] & 2002 & $\begin{array}{l}\text { NSTE-ACS } \\
\text { MV CAD } \\
\text { PCI }\end{array}$ & $\begin{array}{l}>50 \% \\
>70 \%\end{array}$ & $\begin{array}{c}\text { liCV, } \\
\text { Staged } \mathrm{PCl} \\
\text { Prior } \mathrm{CABG} \\
\text { and/or } \mathrm{PCl} \text { in } \\
\text { last } 6 \text { months }\end{array}$ & 290 & $224 / 66$ & 6 months & $\begin{array}{c}\text { Composite } \\
\text { (death/MI/ } \\
\text { hospitalization) } \\
\text { Revascularization }\end{array}$ \\
\hline Shishehbor [42] & 2007 & $\begin{array}{l}\text { NSTE-ACS } \\
\text { MV CAD } \\
\text { PCI } \\
\text { BMS }\end{array}$ & $>50 \%$ & $\begin{array}{c}\text { Staged PCI } \\
\text { Prior CABG } \\
\text { CTO } \\
\text { LM CAD }\end{array}$ & 1240 & $761 / 479$ & $\begin{array}{l}28 \pm 23 \\
\text { months }\end{array}$ & $\begin{array}{l}\text { Composite } \\
\text { (death/MI/ } \\
\text { revascularization) } \\
\text { Components } \\
\text { of composite } \\
\text { end point }\end{array}$ \\
\hline Brener [43] & 2008 & $\begin{array}{l}\text { NSTE-ACS } \\
\text { MV CAD } \\
\text { PCI }\end{array}$ & $>50 \%$ & $\begin{array}{l}\text { Staged PCI } \\
\text { Prior CABG }\end{array}$ & 105866 & $72048 / 33818$ & In hospital & $\begin{array}{c}\text { Death } \\
\text { MI } \\
\text { Revascularization } \\
\text { Success } \\
\text { of procedure } \\
\text { Periprocedural } \\
\text { complications }\end{array}$ \\
\hline Zapata [44] & 2009 & $\begin{array}{l}\text { NSTE-ACS } \\
\text { MV CAD } \\
\text { PCI }\end{array}$ & $>70 \%$ & $\begin{array}{l}\text { Staged } \mathrm{PCl} \\
\text { Prior CABG } \\
\text { CTO }\end{array}$ & 609 & $405 / 204$ & 12 months & $\begin{array}{l}\text { Composite } \\
\text { (death/MI/ } \\
\text { revascularization) } \\
\text { Components } \\
\text { of composite } \\
\text { end point }\end{array}$ \\
\hline Lee [45] & 2011 & $\begin{array}{l}\text { NSTE-ACS } \\
\text { MV CAD } \\
\text { PCI } \\
\text { DES }\end{array}$ & $>50 \%$ & $\begin{array}{c}\text { Prior CABG } \\
\text { LM CAD } \\
\text { CTO } \\
\text { Planned PCI } \\
\text { after } \\
\text { hospitalization }\end{array}$ & 366 & $187 / 179$ & $36 \pm 7$ months & $\begin{array}{l}\text { Composite } \\
\text { (death/MI/ } \\
\text { revascularization) } \\
\text { Components } \\
\text { of composite } \\
\text { end point }\end{array}$ \\
\hline Bauer [46] & 2011 & $\begin{array}{l}\text { NSTE-ACS } \\
\text { MV CAD } \\
\text { PCI }\end{array}$ & $>70 \%$ & $\begin{array}{c}\text { Prior CABG } \\
L M C A D\end{array}$ & 1920 & $1186 / 734$ & In hospital & $\begin{array}{c}\text { Death } \\
\text { MI } \\
\text { Stroke } \\
\text { Major bleeding } \\
\text { Dialysis }\end{array}$ \\
\hline
\end{tabular}

CV PCI - culprit vessel percutaneous coronary intervention, $\mathrm{MV} \mathrm{PCI-multivessel} \mathrm{percutaneous} \mathrm{coronary} \mathrm{intervention,} \mathrm{NSTE-ACS} \mathrm{-} \mathrm{non-ST-elevation} \mathrm{acute}$ coronary syndrome, MV CAD - multivessel coronary artery disease, BMS - bare metal stent implantation, DES - drug-eluting stent implantation, iiCV - inability to identify culprit vessel, CABG - coronary artery bypass graft, LM CAD - left main coronary artery disease, CTO - chronic total occlusion, $\mathrm{MI}$ - myocardial infarction

quantity of accompanying diseases and inferior clinical state.

\section{Culprit vessel identification}

Culprit vessel identification is crucial for further treatment of MV CAD. Culprit vessel localization is identified by the operator, usually based on anatomical and functional evaluation of coronary artery stenosis. In contrast to the STEMI population, in NSTE-ACS patients with MV CAD assessing the culprit vessel based only on the angiographic image can cause many difficulties. Characteristic features of the lesion responsible for ischemia are: irregular borders, eccentricity, ulceration or filling defect, which indicates thrombus [36]. Most of the time juxtaposition of the foregoing image with electrocardiography and echocardiography tests allows us to identify the culprit vessel. Fractional flow reserve (FFR) is indicated for the assessment of the functional consequences of moderate coronary stenoses when functional information is lacking [48-51]. Moreover, some clues about localization can be provided by different diagnostic methods; however, their varied usefulness, low availability and high costs limit their use nowadays [52, 53].

In the analyzed papers about optimal invasive treatment, according to the scheme shown above, identification of the culprit vessel was undertaken by the operator based on angiographic data and changes in the electroand echocardiography test. The FFR was not used in any 
Table 2. Baseline characteristics of patients according to adopted strategy

\begin{tabular}{|c|c|c|c|c|c|c|c|c|c|c|c|c|}
\hline \multirow{3}{*}{$\begin{array}{l}\text { Variable } \\
\text { Group }\end{array}$} & \multicolumn{12}{|c|}{ First investigator of study } \\
\hline & \multicolumn{2}{|c|}{ Brener [41] } & \multicolumn{2}{|c|}{ Shishehbor [42] } & \multicolumn{2}{|c|}{ Brener [43] } & \multicolumn{2}{|c|}{ Zapata [44] } & \multicolumn{2}{|c|}{ Lee [45] } & \multicolumn{2}{|c|}{ Bauer [46] } \\
\hline & $\mathrm{CV} \mathrm{PCl}$ & $\mathrm{MV} \mathrm{PCI}$ & $\mathrm{CV} P C l$ & $\mathrm{MVPCl}$ & $\mathrm{CV} P C l$ & $\mathrm{MVPCl}$ & $\mathrm{CV} P C \mathrm{C}$ & $\mathrm{MV} \mathrm{PCl}$ & $\mathrm{CV} P C l$ & $\mathrm{MVPCl}$ & CV PCl & $\mathrm{MVPCl}$ \\
\hline$N$ & 224 & 66 & 761 & 479 & 72048 & 33818 & 405 & 204 & 187 & 179 & 1186 & 734 \\
\hline $\begin{array}{l}\text { Mean age } \\
\text { [years] }\end{array}$ & $62 \pm 12$ & $62 \pm 11$ & $65 \pm 12$ & $66 \pm 12$ & $66 \pm 9$ & $65 \pm 10$ & $62 \pm 11$ & $61 \pm 10$ & $65 \pm 12$ & $65 \pm 11$ & $67 \pm 11$ & $65 \pm 11$ \\
\hline Male [\%] & 67 & 71 & 65 & 64 & 64 & 64 & 83 & 82 & 63 & 72 & 73 & 69 \\
\hline \multicolumn{13}{|c|}{ Medical history [\%] } \\
\hline NSTEMI & 65 & 75 & - & - & 38 & 33 & - & - & - & - & 48 & 43 \\
\hline Prior MI & 43 & 44 & 47 & 46 & 29 & 25 & 27 & 25 & 8 & 9 & 34 & 34 \\
\hline Prior $\mathrm{PCl}$ & - & - & - & - & 32 & 28 & 17 & 11 & 16 & 8 & 23 & 20 \\
\hline $\begin{array}{l}\text { Cigarette } \\
\text { smoking }\end{array}$ & 26 & 32 & 26 & 19 & 27 & 25 & 31 & 30 & 19 & 25 & 53 & 47 \\
\hline Heart failure & 6 & 5 & - & - & 10 & 10 & - & - & 6 & 6 & 10 & 14 \\
\hline Hypertension & 70 & 64 & - & - & 74 & 73 & 65 & 66 & 63 & 58 & 76 & 70 \\
\hline $\begin{array}{l}\text { Diabetes } \\
\text { mellitus }\end{array}$ & 27 & 30 & $\begin{array}{l}12^{a} \\
19^{b}\end{array}$ & $\begin{array}{l}13^{a} \\
19^{b}\end{array}$ & 32 & 31 & 22 & 20 & 41 & 34 & 30 & 29 \\
\hline Dyslipidemia & 67 & 68 & - & - & 68 & 68 & 62 & 66 & 28 & 32 & 59 & 65 \\
\hline $\begin{array}{l}\text { Family history } \\
\text { of } C A D\end{array}$ & $y-$ & - & 37 & 42 & - & - & - & - & 6 & 7 & - & - \\
\hline $\begin{array}{l}\text { Renal } \\
\text { dysfunction }\end{array}$ & - & - & 6 & 6 & 6 & 5 & 4 & 3 & 6 & 6 & 7 & 5 \\
\hline PAD & - & - & 9 & 10 & 13 & 11 & - & - & 4 & 3 & - & - \\
\hline \multicolumn{13}{|c|}{ Medications at discharge [\%] } \\
\hline ASA & - & - & 94 & 94 & 92 & 92 & - & - & 98 & 98 & - & - \\
\hline ACE-Inh & - & - & 21 & 25 & - & - & - & - & - & - & - & - \\
\hline$\beta$-Blockers & - & - & 47 & 44 & - & - & - & - & 63 & 68 & - & - \\
\hline Statins & - & - & 89 & 81 & - & - & - & - & 78 & 77 & - & - \\
\hline Clopidogrel & - & - & 77 & 82 & 94 & 94 & - & - & 98 & 98 & - & - \\
\hline
\end{tabular}

$C V P C l$ - culprit vessel percutaneous coronary intervention, $M V P C l$ - multivessel percutaneous coronary intervention, $N$-number of patients, $p$ - probability, UA - unstable angina, NSTEMI - non-ST-elevation myocardial infarction, CAD - coronary artery disease, MI-myocardial infarction, PAD - peripheral artery disease, ASA - acetylsalicylic acid, ACE-Inh - angiotensin-converting enzyme inhibitor, ainsulin-dependent diabetes mellitus, ${ }^{b}$ non-insulindependent diabetes mellitus

analysis as an additional diagnostic method in stenosis evaluation. Only in 3 studies did the authors indicate a problem of patients among whom identification of the culprit vessel was not possible [41, 42, 44]; they were excluded from further analysis [41, 42] or automatically assigned to the CV PCI group [44]. Presence of several significant lesions with similar anatomy and functional characteristics can cause inability to identify the culprit vessel among patients with NSTE-ACS. This situation is an important argument in favor of performing MV PCl.

\section{Factors influencing the choice of strategy}

It is worth carefully thinking about other factors that can substantially affects the operator's choice of a particular invasive treatment strategy. Brener et al. reported that factors independently associated with conducting CV versus MV PCI included NSTEMI diagnosis, chronic kidney dis- ease, prior $\mathrm{PCl}$, peripheral vascular disease, older age, cigarette smoking and low left ventricular ejection fraction (Table 3) [43], while among patients suffering from heart failure in NYHA class IV the operator more frequently decided to perform $\mathrm{MV} \mathrm{PCl}$.

Data from angiographic analysis have shown that the choice of strategy is determined by severity, localization of the culprit vessel and presence of chronic total occlusion (CTO) in non-culprit vessels. If one of the lesions was total occlusion of the right coronary artery (RCA) or proximal left anterior descending (LAD), the operator significantly more often decided to perform CV PCI instead of $\mathrm{MV} \mathrm{PCl}$, whereas in the case of different lesion localization multivessel revascularization was more frequently conducted.

Part of the mentioned data was reported in a publication by Bauer et al. [46]. Independent factors influencing 
Table 3. Independent predictors of CV vs. $\mathrm{MV} \mathrm{PCl}$ (Brener et al. [43])

\begin{tabular}{|c|c|c|}
\hline Factor & OR $(95 \% \mathrm{Cl})$ & Value of $p$ \\
\hline \multicolumn{3}{|l|}{ Clinical } \\
\hline NSTEMI vS. UA & $1.29(1.24-1.34)$ & $<0.001$ \\
\hline LVEF (per 10\%) & $0.97(0.95-0.98)$ & $<0.001$ \\
\hline NYHA IV & $0.86(0.78-0.95)$ & $<0.001$ \\
\hline \multicolumn{3}{|l|}{ Medical history } \\
\hline Chronic kidney disease & $1.24(1.14-1.34)$ & $<0.001$ \\
\hline Prior $\mathrm{PCl}$ & $1.14(1.09-1.18)$ & $<0.001$ \\
\hline Peripheral artery disease & $1.12(1.07-1.18)$ & $<0.001$ \\
\hline Older age (per 10 years) & $1.09(1.08-1.11)$ & $<0.001$ \\
\hline Cigarette smoking & $1.08(1.05-1.12)$ & $<0.001$ \\
\hline Prior $\mathrm{CHF}$ & $0.95(0.91-1.00)$ & 0.041 \\
\hline \multicolumn{3}{|c|}{ Angiographic characteristics of culprit vessel } \\
\hline \multicolumn{3}{|l|}{$\overline{L M}$} \\
\hline $100 \%$ (vs. < 70\%) & $0.58(0.35-0.97)$ & $<0.001$ \\
\hline $71-99 \%$ (vs. < 70\%) & $0.25(0.16-0.40)$ & $<0.001$ \\
\hline \multicolumn{3}{|l|}{ pLAD } \\
\hline $100 \%$ (vs. < 70\%) & $1.17(1.06-1.30)$ & $<0.001$ \\
\hline $71-99 \%$ (vs. < 70\%) & $0.49(0.46-0.51)$ & $<0.001$ \\
\hline \multicolumn{3}{|l|}{$\mathrm{m} / \mathrm{dLAD}$} \\
\hline $100 \%$ (vs. < 70\%) & $0.92(0.84-1.02)$ & $<0.001$ \\
\hline $71-99 \%$ (vs. < 70\%) & $0.55(0.52-0.59)$ & $<0.001$ \\
\hline \multicolumn{3}{|l|}{$\overline{L C x}$} \\
\hline $100 \%$ (vs. < 70\%) & $0.71(0.65-0.76)$ & $<0.001$ \\
\hline $71-99 \%$ (vs. < 70\%) & $0.35(0.33-0.37)$ & $<0.001$ \\
\hline \multicolumn{3}{|l|}{ RCA } \\
\hline $100 \%$ (vs. < 70\%) & $1.43(1.32-1.53)$ & $<0.001$ \\
\hline $71-99 \%$ (vs. < 70\%) & $0.51(0.48-0.53)$ & $<0.001$ \\
\hline СTO (other than culprit vessel) & $1.25(1.16-1.36)$ & $<0.001$ \\
\hline \multicolumn{3}{|c|}{$\begin{array}{l}\text { Odds ratio > } 1 \text { implies culprit vessel more likely than multivessel per- } \\
\text { cutaneous coronary intervention, NSTEMI-non-ST-elevation myocar- } \\
\text { dial infarction, UA - unstable angina, LVEF-left ventricular ejection } \\
\text { fraction, NYHA - New York Heart Association, CHF-congestive heart } \\
\text { failure, RCA - right coronary artery, LCX - left circumflex artery, } m / d L A D \\
\text { - mid or distal LAD artery }\end{array}$} \\
\hline
\end{tabular}

the decision to perform culprit vessel PCI were: diagnosed NSTEMI, older age, peripheral vascular disease, ischemic stroke and prior myocardial infarction. In contrast to Brener et al., presence of chronic kidney disease, heart failure and CTO did not affect the decision-making process. Furthermore, occurrence of significant stenosis in distal segments of coronary arteries (segments 3, 4, 8, 9, 10, 14, 15) substantially less often led the operator to perform MV PCI (OR: 0.43; 95\% Cl: 0.32-0.58; $p<0.001$ ).

According to the ESC guidelines in the context of MV $C A D$, one of the arguments in favor of choosing the optimal strategy can be widely available risk scores applied during coronary angiography [17]. Lee et al. in angiographic evaluation assessed the median SYNTAX score and APPROACH lesion score [45]. The results of the first score were similar between the two groups ( $22.4 \pm 10.7$ vs. 23.1 $\pm 9.3 ; p=N S$ ), whereas in the APPROACH lesion score patients above the median had a tendency to undergo MV $\mathrm{PCl}$ more often than those with a score below the median $(56.2 \pm 15.4$ vs. $60.0 \pm 14.3 ; p=0.016)$. In multivariate analysis there was no significant interaction between the treatment strategy and the APPROACH lesion score or the SYNTAX score. Shishehbor et al. analyzed the less common DUKE prognostic score, which assesses the complexity of coronary artery stenoses based on their degree and location [42]. Patients treated with MV PCI had a significantly higher score ( $34 \pm 14$ vs. $36 \pm 14$; $p=0.008$ ); however, when only patients with severe multivessel coronary artery disease (at least 2 critical stenoses $>95 \%$ in 2 coronary arteries; DUKE prognostic score $\geq 42$ ) were analyzed, there were no statistically significant differences between the groups ( $20 \%$ vs. $20 \%$; $p=N S$ ). Nevertheless, in the discussed subject there is still a need for further studies in order to define the role of mentioned scores in selecting the proper $\mathrm{PCl}$ strategy or to create new scores facilitating the decision-making process.

\section{Efficacy and safety of CV PCI compared to MV PCI}

So far, no randomized studies have been conducted in order to compare CV vs. MV PCI in the NSTE-ACS population. Data from in-hospital and long-term outcomes according to the selected strategy are contained in Table 4.

The TACTICS-TIMI 18 subanalysis included 427 patients with NSTE-ACS treated with $\mathrm{PCl} ; 137$ patients manifested single vessel coronary artery disease and the remainder 290 multivessel coronary artery disease, of whom 224 were treated with $\mathrm{CV} \mathrm{PCl}$ and 127 were qualified for multivessel revascularization [41]. There were no significant differences in occurrence of major adverse cardiac events between CV and MV PCl groups during 30 days (9.4\% vs. 7.6\%; $p=\mathrm{NS}$ ) and 6-month follow-up ( $23.2 \%$ vs. $21.2 \%$; $p=\mathrm{NS})$; however, it should be noted that non-target vessel revascularization was performed statistically significantly more often in the CV PCI group (6.3\% vs. $1.5 \% ; p=0.04$ ). Modifying the threshold for the definition of significant coronary artery disease from $50 \%$ to $70 \%$ resulted in similar outcomes with even greater need for repeat revascularization $(7.7 \%$ vs. $1.7 \% ; p=0.001)$. It is worth mentioning that this study included patients with prior CABG at least 6 months before the current procedure (total $64 ; 21 \%$ vs. $24 \% ; p=0.001)$. Presence of both unobstructed and stenosed grafts can substantially affect the operator's decision on strategy selection and consequently treatment outcomes.

This problem was avoided in subsequent analyses, where prior CABG was one of the exclusion criteria. Shishehbor et al. analyzed 1240 patients, 479 of whom underwent multivessel and 761 culprit-only stenting. A particular element of this study is that all patients underwent $\mathrm{PCl}$ 
Table 4. In-hospital and long-term prognosis according to adopted strategy

\begin{tabular}{|c|c|c|c|c|c|}
\hline First investigator of study & Follow-up & End points & CV PCI \% & MV PCI \% & Value of $p$ \\
\hline \multirow[t]{5}{*}{ Brener [41] } & \multirow[t]{5}{*}{6 months } & Composite & 23.2 & 21.2 & NS \\
\hline & & Death & 2.2 & 3.0 & NS \\
\hline & & $\mathrm{MI}$ & 8.0 & 6.1 & NS \\
\hline & & TVR & 13.8 & 10.6 & NS \\
\hline & & Non-TVR & 6.3 & 1.5 & 0.04 \\
\hline \multirow[t]{4}{*}{ Shishehbor [42] } & \multirow[t]{4}{*}{$28 \pm 23$ months } & Composite & 36.0 & 35.1 & 0.04 \\
\hline & & Death/MI & 18.3 & 18.8 & NS \\
\hline & & Death & 13.1 & 15.0 & NS \\
\hline & & Revascularization & 22.5 & 20.0 & NS \\
\hline \multirow[t]{9}{*}{ Brener [43] } & \multirow[t]{9}{*}{ In hospital } & Death & 1.3 & 1.2 & $<0.001$ \\
\hline & & $\mathrm{MI}$ & 1.1 & 1.5 & $<0.001$ \\
\hline & & Cardiogenic shock & 0.8 & 0.8 & $<0.001$ \\
\hline & & Heart failure & 0.8 & 0.7 & $<0.001$ \\
\hline & & Cardiac tamponade & 0.1 & 0.1 & NS \\
\hline & & Bleeding & 1.7 & 1.8 & NS \\
\hline & & Renal failure & 1.0 & 1.0 & NS \\
\hline & & Emergency repeated $\mathrm{PCl}$ & 0.2 & 0.1 & 0.001 \\
\hline & & Unplanned CABG & 0.8 & 0.3 & 0.03 \\
\hline \multirow[t]{6}{*}{ Zapata [44] } & \multirow[t]{6}{*}{12 months } & Composite & 16.4 & 9.4 & 0.02 \\
\hline & & Death & 1.98 & 1.99 & NS \\
\hline & & $\mathrm{MI}$ & 1.2 & 0.5 & NS \\
\hline & & Revascularization & 13.9 & 7.5 & 0.04 \\
\hline & & $\overline{\mathrm{PCl}}$ & 8.9 & 6.0 & NS \\
\hline & & $\overline{C A B G}$ & 5.7 & 1.5 & 0.01 \\
\hline \multirow[t]{5}{*}{ Lee [45] } & \multirow[t]{5}{*}{$36 \pm 7$ months } & Composite & 32.6 & 19.6 & 0.001 \\
\hline & & Death & 7.0 & 6.1 & NS \\
\hline & & $\mathrm{MI}$ & 4.8 & 3.4 & NS \\
\hline & & TVR & 16.0 & 11.2 & NS \\
\hline & & Non-TVR & 19.8 & 3.4 & 0.001 \\
\hline
\end{tabular}

Statistical methods: [49] analysis of variance for the three groups (ANOVA), [51] p-value for adjusted hazard ratio (HR), [52] p-value for $x^{2}$ test layer, [53] $p$-value for the coefficient of relative risk (RR), [54] p-value adjusted hazard ratio (HR), [55] p-value for the adjusted odds ratio (OR)

only with bare metal stent implantation [42]. There were no differences in complications such as periprocedural myocardial infarction or acute kidney injury between the groups. During an average of $2.3 \pm 2.0$ years of follow-up, $\mathrm{MV} \mathrm{PCl}$ was associated with an independent impact on improvement prognosis (HR: 0.80; 95\% Cl: 0.64-0.99; $p=0.04)$, mainly because of a trend towards reducing the need for repeat revascularization (HR: 0.78 ; $95 \% \mathrm{Cl}$ : 0.59$1.03 ; p=0.07$ ). Using propensity-score matching, after eliminating differences in baseline characteristics this trend became statistically significant (HR: 0.59; $95 \% \mathrm{Cl}$ : 0.41$0.84 ; p=0.003)$.

The largest amount of data on prognosis and in-hospital complications depending on the adopted strategy was provided in a publication by Brener et al., reporting on a large group of 105866 patients [43]. In 77\% of patients operators decided to perform CV and in 23\% MV PCl. Single vessel procedure was associated with a higher procedure success rate ( $91 \%$ vs. $88 \% ; p<0.001)$. More frequent occurrence of myocardial infarction during hospitalization was observed in the $\mathrm{MV} \mathrm{PCl}$ group $(1.1 \%$ vs. $1.5 \%$; $p<0.001)$, while the percentage of patients with cardiogenic shock, cardiac tamponade, bleeding or patients who underwent CV $\mathrm{PCl}$ needed more often repeat revascularization already during hospitalization ( $0.19 \%$ vs. $0.12 \% ; p=0.03)$ and CABG $(0.79 \%$ vs. $0.28 \% ; p<0.001)$. However, the foregoing data did not lead to improved in-hospital outcomes (1.3 vs. 1.2; $p=0.09$ ). An important disadvantage of Brenner's analysis is the lack of long-term follow-up of the studied population.

Zapata et al. came to similar conclusions after analyzing 609 patients who presented at least two major coronary vessels with a visual stenosis $\geq 70 \%$. Four hundred 
and five underwent CV PCI and 204 MV PCI [44]. During 1-year follow-up the number of major adverse cardiac events was significantly higher in the CV PCI group (16.34\% vs. $9.45 \% ; p=0.02$ ), which was associated with more frequent need for repeat revascularization $(13.86 \%$ vs. $7.46 \%$; $p=0.04)$. In multivariate analysis procedure limited to the culprit vessel was an independent factor influencing 1-year mortality (OR: 1.66, 95\% Cl: 1.12-3.47, $p=0.01$ ).

Because of technological progress in invasive treatment Lee et al. decided to focus only on patients with implanted drug-eluting stents [45]. They analyzed a total of 366 patients; 187 were assigned to the culprit vessel $\mathrm{PCI}$ group and 179 to the multivessel $\mathrm{PCl}$ group. It is worth mentioning that in this study as opposed to the one previously discussed, the MV PCl group included patients who underwent both single and staged procedures, during single hospitalization; however, the authors did not present data on mean postponement time to the second. As in previous studies, culprit vessel revascularization was associated with more frequent occurrence of major adverse cardiac events ( $32.6 \%$ vs. $19.6 \% ; p=0.003$ ), mostly because of necessity to perform repeat revascularization (28.9\% vs. $13.4 \% ; p<0.001$ ). Death for all cause and myocardial infarction rates were comparable between the two groups. Multivariate analysis showed that $\mathrm{MV} \mathrm{PCl}$ is an independent predictor of more favorable prognosis in $36 \pm 6.5$-month follow-up (HR: 0.50; 95\% Cl: 0.30-0.85; $p=0.01$ ).

Bauer et al. studied in-hospital outcomes of 1920 consecutive patients with NSTE-ACS and MV CAD from the Euro Heart Survey registry [46]. CV PCI was performed in 1186 and $\mathrm{MV} \mathrm{PCl}$ in 734 patients. The authors found that multivessel PCI was associated with more frequent occurrence of periprocedural myocardial infarction (1.8 vs. 5.3; $p<0.0001)$, whereas death, stroke, major bleeding and urgent dialysis rates were similar in both groups. The authors did not provide long-term follow-up analysis.

\section{Staged procedure strategy}

According to ESC guidelines on myocardial revascularization, after stabilization of the clinical condition among patients who underwent intervention in the culprit vessel responsible for NSTE-ACS, the therapeutic decision regarding the remaining stenosed vessel can be based on stable coronary artery disease recommendations [17]. During the staged procedure remaining arteries should be treated as in a patient with stable CAD, after myocardial infarction with presence of one or two vessel coronary artery disease. Data on death risk in patients suffering from stable CAD treated with $\mathrm{PCl}$ compared to conservative treatment are inconclusive, but most meta-analyses indicate significant reduction of repeat revascularization in the group of patients treated primarily with the invasive strategy [5660]. In one meta-analysis including 7513 patients, the authors demonstrated dominance of $\mathrm{PCl}$ over conservative treatment in reduction of mortality in 51-month fol- low-up (7.4\% vs. 8.7\%; $20 \%$ OR reduction) [58]. Furthermore, this effect was even more beneficial among patients with a history of recent ( $<4$ weeks) myocardial infarction (35\% OR reduction in group treated with $\mathrm{PCl}$ compared to conservative treatment group).

However, in NSTE-ACS population data on staged procedures outcomes are very limited. Despite the fact that in some analyzed studies the inclusion criteria allowed performed staged $\mathrm{PCl}$, the authors did not try to conduct deeper analysis of this subject [45]. One of Brener's study elements was in-hospital efficacy and safety of multivessel revascularization conducted in a single procedure $(n=33818)$, compared to a staged procedure during single hospitalization ( $n=5298)$ [43]. Staged revascularization was associated with higher mortality $(2.1 \%$ vs. $1.2 \% ; p<$ $0.0001)$, more frequent presence of myocardial infarction (3.5\% vs. $1.5 \%$; $p<0.0001)$, cardiogenic shock (1.23\% vs. $0.76 \% ; p<0.0001)$ and repeat $\mathrm{PCl}$ during in-hospital observation $(0.23 \%$ vs. $0.12 \% ; p<0.001)$, but unplanned cardiac surgery was conducted less often ( 0.13 vs. $0.28 ; p=0.03$ ).

\section{Prognosis in selected groups of patients}

Having regard to presented outcomes, it seems that due to the large heterogeneity of the NSTE-ACS population and diversity in angiographic image, not every patient may benefit from multivessel revascularization.

Long before introduction of the currently valid definition of NSTE-ACS, several investigators attempted to evaluate $\mathrm{MV} \mathrm{PCl}$ among patients with unstable angina (UA). Already in 1986 deFeyer et al. in a retrospective study on a small group of 154 patients stated that abandonment of revascularization in non-culprit vessels in MV CAD is associated with more frequent recurrence of clinical symptoms not affecting other treatment outcomes in 6-month follow-up compared to the control croup with single vessel CAD ( $29 \%$ vs. $16 \% ; p<0.05)$ [37]. The study by Grassman et al. in a population of 386 patients with UA and MV CAD showed that performing multivessel balloon angioplasty compared to a procedure limited to the culprit vessel is associated with worse in-hospital outcomes (OR: 1.72; 95\% Cl: 1.11-2.66; $p=0.014$ ) [38]. Dellavalle et al. based on data from 571 patients with UA observed that both $\mathrm{PCl}$ ad hoc $(p=0.007)$ and implantation of $>1$ stent $(p=0.0008)$ during a single procedure are independent predictors of worse in-hospital outcomes [39]. The group under leadership of Mariani came to similar conclusions, after analyzing 208 patients with UA and MV CAD [40]. Ad hoc PCl and implantation of multiple stents was associated with adverse in-hospital treatment outcomes (respectively: OR: 4.51; $95 \% \mathrm{Cl}: 1.11-18.3, p=0.035$ and OR: 5.44 ; $95 \% \mathrm{Cl}: 1.21-$ 24.3, $p=0.027$ ) compared to postponed angioplasty after coronary angiography and single stent implantation. There were no significant differences between the groups in percentage of deaths, repeat myocardial infarctions and revascularizations during in-hospital and 1-year follow-up. 
Authors of the foregoing studies on patients with UA suggest that the mentioned results testify to the higher percentage of complications during multivessel intervention compared to intervention restricted to the culprit vessel. Reduction of adverse cardiovascular events after performing a multivessel procedure was lower or similar to culprit vessel intervention.

In contrast to the presented studies, Kim et al. decided to concentrate on an NSTEMI population [47]. They decided to analyze 1919 patients, among whom 908 underwent culprit vessel and 1011 multivessel PCl. The study design allowed staged procedures in the same hospitalization. During in-hospital observation mortality in the CV PCl group was significantly higher (2.9\% vs. $1.4 \%$; $p=0.025)$ without differences in periprocedural complications, cardiogenic shock or acute kidney injury. After a period of 1-year follow-up the authors observed that culprit vessel revascularization was related to more frequent presence of adverse cardiovascular events ( $18.6 \%$ vs. $12.9 \%$; $p=0.002)$, mainly because of a higher death rate $(6.4 \%$ vs. $3.5 \% ; p=0.009)$ and repeat myocardial infarction $(2.1 \%$ vs. $0.6 \% ; p=0.012$ ) compared to the MV PCl group. Furthermore, angioplasty restricted to the culprit vessel was associated with a statistically non-significant trend towards repeat revascularization of culprit ( 1.7 vs. $0.6 ; p=0.052)$ and non-culprit vessels ( $4.6 \%$ vs. $2.8 \% ; p=0.075$ ).

Before drawing conclusions from the foregoing studies, it should be considered that those analyses were conducted on a UA population before introduction of cardiovascular risk assessment algorithms and related decisions of the further treatment process. Moreover, considerable progress in invasive and conservative treatment can undermine the results from these analyses. Nevertheless, together with Kim's study on an NSTEMI population, they indicate the necessity of precise risk stratification both before making a decision of invasive treatment and during the eventual intervention.

\section{Future research directions}

Besides typical limitations of the retrospective character of existing studies, several important issues should be noted. Tests enabling functional assessment of lesions were not used in any study. Research conducted in patients with stable coronary artery disease shows that use of FFR in $32 \%$ of cases results in changing the treatment decision based on coronary angiography [51]. Accurate analysis of lesions could allow more effective identification of the culprit vessel and influence the decision on any intervention in the remaining vessels and consequently restrict implications related to multivessel procedures. Several analyses show that not all patients with NSTE-ACS equally gain benefits from multivessel revascularization. It is worth taking steps to select patient groups in which performing multivessel PCI would come with the most optimal results in reducing adverse cardiovascular events. Moreover, there is a need to conduct further studies in the aspect of staged multivessel $\mathrm{PCl}$, with particular attention to time from primary culprit vessel $\mathrm{PCI}$ to the subsequent procedure in the remaining vessels.

\section{Cardiac societies' recommendations}

ESC guidelines on revascularization in NSTE-ACS recommend ad hoc $\mathrm{PCl}$ directly after coronary angiography only in the culprit vessel [17]. Intervention in other vessels should be performed after heart team consultations or according to the institutional protocol. The decision should be individualized and dependent on the general condition of the patient, lesion characteristics and degree of myocardial damage [16, 17]. The American Society of Cardiology advises performing MV PCl "when there is a high likelihood of success and a low risk of morbidity and the vessel(s) to be dilated subtend a moderate or large area of viable myocardium and have high risk by noninvasive testing" [18]. Neither European nor American guidelines include detailed recommendations and algorithms, which is due to lack of sufficient research, especially prospective multicenter randomized trials.

\section{Conclusions}

The presented data suggest that multivessel coronary intervention, despite a lack of impact on mortality and percentage of repeat myocardial infarction, is associated with a lower repeat revascularization rate compared to $\mathrm{CV} \mathrm{PCl}$. Current studies on the NSTE-ACS population indicate similar safety of both strategies. The choice between intervention limited to the culprit vessel and MV PCI rests mostly on the operator. According to guidelines this decision should be made based on the general clinical condition of patients, possibility of culprit vessel identification, lesion characteristics and degree of myocardial damage. It is necessary to precisely conduct cardiovascular risk stratification, allowing a reduction of complications related to the prolonged time of the procedure.

Summing up, data from existing papers suggest that the balance of benefits and risks related to further interventional procedures should be based on: (1) analysis of patient's general condition, (2) cardiovascular risk factors, (3) possibility of culprit vessel identification, (4) technical feasibility of performing multivessel procedure, (5) localization and degree of stenosis of hemodynamically significant stenoses. Furthermore, analyzing exclusion criteria, it is worth mentioning, which also influences the decision, (6) prior coronary artery bypass grafting and left main stenosis. Moreover, patient's hemodynamic stability, operator's experience, heart team consultation and availability of cardiac surgery facilities could be arguments influencing the choice of optimal treatment strategy.

Due to the serious limitations and diversity in methodology, it is essential to conduct further studies towards optimization of the percutaneous coronary intervention strategy among patients with NSTE-ACS and MV CAD. The 
lack of prospective randomized trials is worth mentioning. Maybe their future implementation will allow selection of individual patient groups from the NSTE-ACS population which will gain the most benefits from revascularization of every hemodynamically significant lesion.

\section{References}

1. Yeh RW, Sidney S, Chandra M, et al. Population trends in the incidence and outcomes of acute myocardial infarction. N Engl J Med 2010; 362: 2155-2165.

2. Gierlotka M, Gasior M, Wilczek K, et al. Temporal Trends in the Treatment and Outcomes of Patients With Non-ST-Segment Elevation Myocardial Infarction in Poland from 2004-2010 (from the Polish Registry of Acute Coronary Syndromes). Am J Cardiol 2012; 109: 779-786

3. Yan AT, Yan RT, Tan M, et al. In-hospital revascularization and oneyear outcome of acute coronary syndrome patients stratified by the GRACE risk score. Am J Cardiol 2005; 96: 913-916.

4. Mehta SR, Granger CB, Boden WE, et al. Early versus delayed invasive intervention in acute coronary syndromes. $\mathrm{N} \mathrm{Engl} \mathrm{J} \mathrm{Med}$ 2009; 360: 2165-2175.

5. Sorajja P, Gersh BJ, Cox DA, et al. Impact of delay to angioplasty in patients with acute coronary syndromes undergoing invasive management: analysis from the ACUITY (Acute Catheterization and Urgent Intervention Triage strategY) trial. J Am Coll Cardiol 2010; 55: 1416-1424.

6. Mehta SR, Cannon CP, Fox KA, et al. Routine vs selective invasive strategies in patients with acute coronary syndromes: a collaborative meta-analysis of randomized trials. JAMA 2005; 293: 2908-2917.

7. Bavry AA, Kumbhani DJ, Rassi AN, et al. Benefit of early invasive therapy in acute coronary syndromes: a metaanalysis of contemporary randomized clinical trials. J Am Coll Cardiol 2006; 48: 1319-1325.

8. O'Donoghue M, Boden WE, Braunwald E, et al. Early invasive vs conservative treatment strategies in women and men with unstable angina and non-ST-segment elevation myocardial infarction: a meta-analysis. JAMA 2008; 300: 71-80.

9. Fox KA, Clayton TC, Damman P, et al. Long-term outcome of a routine versus selective invasive strategy in patients with nonST-segment elevation acute coronary syndrome a meta-analysis of individual patient data. J Am Coll Cardiol 2010; 55: 2435-2445.

10. Katritsis DG, Siontis GC, Kastrati A, et al. Optimal timing of coronary angiography and potential intervention in non-STelevation acute coronary syndromes. Eur Heart J 2010; 32: 32-40.

11. Boden WE, O'Rourke RA, Crawford MH, et al. Veterans Affairs NonQ-Wave Infarction Strategies in Hospital (VANQWISH) Trial Investigators. Outcomes in patients with acute non-Q-wave myocardial infarction randomly assigned to an invasive as compared with a conservative management strategy. N Engl J Med 1998; 338: 1785-1792.

12. Invasive compared with non-invasive treatment in unstable coronary-artery disease: FRISC II prospective randomized multicentre study. FRagmin and Fast Revascularisation during InStability in Coronary artery disease Investigators. Lancet 1999; 354: 708-715.

13. Neumann FJ, Kastrati A, Pogatsa-Murray G, et al. Evaluation of prolonged antithrombotic pretreatment ('cooling-off' strategy) before intervention in patients with unstable coronary syndromes: a randomized controlled trial. JAMA 2003; 290: 1593-1599.
14. Rasoul S, Ottervanger JP, de Boer MJ, et al. A comparison of dual vs. triple antiplatelet therapy in patients with non-ST-segment elevation acute coronary syndrome: results of the ELISA-2 trial. Eur Heart J 2006; 27: 1401-1407.

15. Montalescot G, Cayla G, Collet JP, et al. Immediate vs delayed intervention for acute coronary syndromes: a randomized clinical trial. JAMA 2009; 302: 947-954.

16. Hamm C, Bassand JP, Agewall S, et al. ESC Guidelines for the management of acute coronary syndromes in patients presenting without persistent ST-segment elevation. The Task Force for the management of acute coronary syndromes (ACS) in patients presenting without persistent ST-segment elevation of the European Society of Cardiology (ESC). Eur Heart J 2011; 32: 2999-3054.

17. Wijns W, Kolh P, Danchin N, et al. Guidelines on myocardial revascularization: the Task Force on Myocardial Revascularization of the European Society of Cardiology (ESC) and the European Association for Cardio-Thoracic Surgery (EACTS). Eur Heart J 2010; 31: 2501-2555.

18. Wright RS, Anderson JL, Adams CD, et al. 2011 ACCF/AHA Focused Update of the Guidelines for the Management of Patients With Unstable Angina/Non -ST-Elevation Myocardial Infarction (Updating the 2007 Guideline): A Report of the American College of Cardiology Foundation/American Heart Association Task Force on Practice Guidelines. Circulation 2011; 123: 2022-2060.

19. Serruys PW, Morice MC, Kappetein AP, et al. Percutaneous coronary intervention versus coronary-artery bypass grafting for severe coronary artery disease. N Engl J Med 2009; 360: 961-972.

20. Jaski BE, Cohen JD, Trausch J, et al. Outcome of urgent percutaneous transluminal coronary angioplasty in acute myocardial infarction: comparison of single-vessel versus multivessel coronary artery disease. Am Heart J 1992; 124: 1427-1433.

21. Sorajja P, Gersh BJ, Cox DA, et al. Impact of multivessel disease on reperfusion success and clinical outcomes in patients undergoing primary percutaneous coronary intervention for acute myocardial infarction. Eur Heart J 2007; 28: 1709-1716.

22. Ben-Gal Y, Moses JW, Mehran R, et al. Surgical versus percutaneous revascularization for multivessel disease in patients with acute coronary syndromes: analysis from the ACUITY (Acute Catheterization and Urgent Intervention Triage Strategy) trial. JACC Cardiovasc Interv 2010; 3: 1059-1067.

23. Buffon A, Biasucci LM, Liuzzo G, et al. Widespread coronary inflammation in unstable angina. N Engl J Med 2002; 347: 5-12.

24. Hanratty CG, Koyama Y, Rasmussen HH, et al. Exaggeration of nonculprit stenosis severity during acute myocardial infarction: implications for immediate multivessel revascularization. J Am Coll Cardiol 2002; 40: 911-916.

25. Chan MY, Andreotti F, Becker RC. Hypercoagulable states in cardiovascular disease. Circulation 2008; 118: 2286-2297.

26. Ohashi Y, Kawashima S, Mori T, et al. Soluble CD40 ligand and interleukin- 6 in the coronary circulation after acute myocardial infarction. Int J Cardiol 2006; 112: 52-58.

27. Bauters C, Hubert E, Prat A, et al. Predictors of restenosis after coronary stent implantation. J Am Coll Cardiol 1998; 31: 1291-1298.

28. Kastrati A, Schomig A, Elezi S, et al. Predictive factors of restenosis after coronary stent placement. J Am Coll Cardiol 1997; 30: 1428-1436.

29. Feit F, Voeltz MD, Attubato MJ, et al. Predictors and impact of major hemorrhage on mortality following percutaneous coronary intervention from the REPLACE-2 Trial. Am I Cardiol 2007; 100: 1364-1369. 
30. Ndrepepa G, Berger PB, Mehilli J, et al. Periprocedural bleeding and 1-year outcome after percutaneous coronary interventions appropriateness of including bleeding as a component of a quadruple end point. J Am Coll Cardiol 2008; 51: 690-697.

31. Ghazzal Z, Ashfaq S, Morris DC, et al. Prognostic implication of creatine kinase release after elective percutaneous coronary intervention in the pre-IIb/IIla antagonist era. Am Heart J 2003; 145: 1006-1012.

32. Ioannidis JP, Karvouni E, Katritsis DG. Mortality risk conferred by small elevations of creatine kinase-MB isoenzyme after percutaneous coronary intervention. J Am Coll Cardiol 2003; 42: 1406-1411.

33. Bhatt DL, Topol EJ, Cutlip DE, et al. Does creatinine kinase-MB elevation after percutaneous coronary intervention predict outcomes in 2005? Circulation 2005; 112: 906-915.

34. Marenzi G, Lauri G, Assanelli E, et al. Contrast-induced nephropathy in patients undergoing primary angioplasty for acute myocardial infarction. J Am Coll Cardiol 2004; 44: 1780-1785.

35. Aspelin P, Aubry P, Fransson SG, et al. Nephrotoxic effects in highrisk patients undergoing angiography. N Engl J Med 2003; 348: 491-499.

36. Fuster V, Moreno PR, Fayad ZA, et al. Atherothrombosis and highrisk plaque part I: evolving concepts. J Am Coll Cardiol 2005; 46: 937-954.

37. deFeyter PJ, Serruys PW, Arnold A, et al. Coronary angioplasty of the unstable angina related vessel in patients with multivessel disease. Eur Heart J 1986; 7: 460-467.

38. Grassman ED, Leya F, Johnson SA, et al. Percutaneous transluminal coronary angioplasty for unstable angina: predictors of outcome in a multicenter study. J Thromb Thrombolysis 1994; 1: 73-78.

39. Dellavalle A, De Servi S, Repetto S, et al. Coronary angioplasty in patients with unstable angina: clinical, electrocardiographic and angiographic predictors of in-hospital outcome. ROSAI Study Group. Ital Heart J 2000; 1: 555-561.

40. Mariani G, De Servi S, Dellavalle A, et al. Complete or incomplete percutaneous coronary revascularization in patients with unstable angina in stent era: are early and one-year results different? Cathet Cardiovasc Interv 2001; 54: 448-453.

41. Brener SJ, Murphy SA, Gibson CM, et al. Efficacy and safety of multivessel percutaneous revascularization and tirofiban therapy in patients with acute coronary syndromes. Am J Cardiol 2002; 90: 631-633.

42. Shishehbor MH, Lauer MS, Singh IM, et al. In unstable angina or non-ST-segment acute coronary syndrome, should patients with multivessel coronary artery disease undergo multivessel or culpritonly stenting? J Am Coll Cardiol 2007; 49: 849-854.

43. Brener SJ, Milford-Beland S, Roe MT, et al. Culprit-only or multivessel revascularization in patients with acute coronary syndrome: an American College of Cardiology National Cardiovascular Database Registry report. Am Heart J 2008; 155: 140-146.

44. Zapata GO, Lasave LI, Kozak F, et al. Culprit-only or multivessel percutaneous coronary stenting in patients with non-ST-segment elevation acute coronary syndrome: one-year follow-up. J Interv Cardiol 2009; 22: 329-335.

45. Lee HJ, Song YB, Hahn JY, et al. Multivesselvs single-vessel revascularization in patients with non-ST-segment elevation acute coronary syndrome and multivessel disease in the drug-eluting stent era. Clin Cardiol 2011; 34: 160-165.

46. Bauer T, Zeymer U, Hochadel M, et al. Prima-vista multi-vessel percutaneous coronary intervention in haemodynamically stable patients with acute coronary syndromes: analysis of over 4.400 patients in the EHS-PCI registry. Int J Cardiol 2011 [Epub ahead of print].

47. Kim MC, Jeong MH, Ahn Y, et al. What is optimal revascularization strategy in patients with multivessel coronary artery disease in non-ST-elevation myocardial infarction? Multivessel or culprit-only revascularization. Int J Cardiol 2011; 153: 148-153.

48. Pijls NH, van Schaardenburgh P, Manoharan G, et al. Percutaneous coronary intervention of functionally nonsignificant stenosis: 5year follow-up of the DEFER Study. J Am Coll Cardiol 2007; 49: 2105-2111.

49. Tonino PA, de Bruyne $\mathrm{B}$, Pijls $\mathrm{NH}$, et al. Fractional flow reserve versus angiography for guiding percutaneous coronary intervention. N Engl J Med 2009; 360: 213-224.

50. Sels JE, Tonino PA, Siebert U, et al. Fractional flow reserve in unstable angina and non-ST-segment elevation myocardial infarction. Experience From the FAME (Fractional flow reserve versus Angiography for Multivessel Evaluation) Study. JACC Cardiovascular Intervention 2011; 11: 1183-1189.

51. Sant'Anna FM, Silva EE, Batista LA, et al. Influence of routine assessment of fractional flow reserve on decision making during coronary interventions. Am J Cardiol 2007; 99: 504-508.

52. Rioufol G, Finet G, Ginon I, et al. Multiple atherosclerotic plaque rupture in acute coronary syndrome: a three-vessel intravascular ultrasound study. Circulation 2002; 106: 804-808.

53. Kubo T, Imanishi T, Takarada S, et al. Assessment of culprit lesion morphology in acute myocardial infarction: ability of optical coherence tomography compared with intravascular ultrasound and coronary angioscopy. J Am Coll Cardiol 2007; 50: 933-939.

54. Huang WC, Wu MT, Chiou KR, et al. Assessing culprit lesions and active complex lesions in patients with early acute myocardial infarction by multidetector computed tomography. Circ J 2008; 72 : 1806-1813.

55. Lønnebakken MT, Staal ME, Nordrehaug JE, et al. Usefulness of contrast echocardiography for predicting the severity of angiographic coronary disease in non-ST-elevation myocardial infarction. Am J Cardiol 2011; 107: 1262-1267.

56. Bucher HC, Hengstler P, Schindler C, et al. Percutaneous transluminal coronary angioplasty versus medical treatment for nonacute coronary heart disease: meta-analysis of randomized controlled trials. BMJ 2000; 321: 73-77.

57. Katritsis DG, Ioannidis JP. Percutaneous coronary intervention versus conservative therapy in nonacute coronary artery disease: a meta-analysis. Circulation 2005; 111: 2906-2912.

58. Schomig A, Mehilli J, de Waha A, et al. A meta-analysis of 17 randomized trials of a percutaneous coronary intervention-based strategy in patients with stable coronary artery disease. J Am Coll Cardiol 2008; 52: 894-904.

59. Jeremias A, Kaul S, Rosengart TK, et al. The impact of revascularization on mortality in patients with non-acute coronary artery disease. Am J Med 2009; 122: 152-161.

60. Hlatky MA, Boothroyd DB, Bravata DM, et al. Coronary artery bypass surgery compared with percutaneous coronary interventions for multivessel disease: a collaborative analysis of individual patient data from ten randomised trials. Lancet 2009; 373: 1190-1197. 